\title{
The Role of Experimental Studies in Design Research
}

\author{
Cash, Philip; Culley, Steve
}

Published in:

The Routledge Companion to Design Research

Publication date:

2015

Link back to DTU Orbit

Citation (APA):

Cash, P., \& Culley, S. (2015). The Role of Experimental Studies in Design Research. In P. A. Rodgers, \& J. Yee (Eds.), The Routledge Companion to Design Research (pp. 175-189). RoutledgeFalmer.

\section{General rights}

Copyright and moral rights for the publications made accessible in the public portal are retained by the authors and/or other copyright owners and it is a condition of accessing publications that users recognise and abide by the legal requirements associated with these rights.

- Users may download and print one copy of any publication from the public portal for the purpose of private study or research.

- You may not further distribute the material or use it for any profit-making activity or commercial gain

- You may freely distribute the URL identifying the publication in the public portal

If you believe that this document breaches copyright please contact us providing details, and we will remove access to the work immediately and investigate your claim 


\section{Please cite as:}

Cash P, Culley S (2014) The Role of Experimental Studies in Design Research. In: Rodgers P, Yee J (eds) Routledge Companion to Design Research, Routledge, Chapter 14, pp 175-189

\section{The Role of Experimental Studies in Design Research}

Philip Cash - DTU, Denmark

Steve Culley - University of Bath, UK

\section{$1 \quad$ Introduction}

In the context of design research, experimental studies play a key role, accounting for a significant number of research publications in journals such as Design Studies, Research in Engineering Design and the Journal of Engineering Design. Further, design experimentation has been used extensively over the last forty years (Cross, 2007). Recent examples include Bar-Eli's (2013) work on sketching, Corremans' (2009) work on design methods and Cai et al.'s (2010) work on sources of inspiration. Experimental studies form a fundamental part of design research by supporting both theory building and theory testing whilst also providing a flexible and readily accessible research approach (Stempfle and Badke-Schaub, 2002). However, with this increased popularity and more extensive scope of use comes the ongoing issue of ensuring research quality and effective implementation in, what frequently are, ever more complex situations (Blessing and Chakrabarti, 2009).

In this context there seems to be both a perceived and an actual lack of scientific rigour, particularly with regard to the use of experimental methods from other fields and the application and development of effective, field specific, experimental research methodology. This has been highlighted by a number of authors over the course of design research history, including Dorst (2008), Blessing and Chakrabarti (2009) and others (Finger and Dixon, 1989a, 1989b, Reich, 1994, 1995). As the field has developed, so to, has the complexity of the studies being undertaken and so developing and using effective experimental methods has become critical to the future of rigorous design research. It would seem that the improvement of experimental methods has been hampered by a lack of field specific discussion and development (i.e. methods developed within the context of, 
and specific to a distinct field of research). Throughout this text the following definitions have been used to delineate the scope of the discussion (Oxford, 2010):

- Experimental studies - the action of putting anything to proof, often arbitrating between competing hypotheses.

- Experimental methods - the characteristic set of procedures employed (more or less systematically) as the primary mode of investigation in experimental studies.

This lack of field specific discussion has been consistently highlighted as a key issue (Ball and Ormerod, 2000, Reich, 1995, Antonsson, 1987, Dixon, 1987), with these authors stressing the need for field specific development of methods, methodology and theory. With this increasing scope and lack of field specific development comes a number of methodological issues (Cash et al., 2012). Specific to experimental study three key issues are:

1. The complexity of the dynamic effects on human behaviour in the research context. This is manifested in the form of detrimental experimental effects (Section 2), which affect all aspects of human behaviour in a research setting. This issue is further confused by the Hawthorne effect - a term used extensively in related fields to describe the general result of experimental effects but not a specific effect itself.

2. The difficulty in controlling for subjectivity and other experimental effects. This issue has led to the development of Placebo controls (Section 3) in many of the fields closely related to design research.

3. The problem of linking experimental study to reality (Cash, 2012). This issue is underpinned by the difficulty in establishing the external validity of discreet experimental studies when examining complex multifaceted phenomena. This can be characterised as linking laboratory and practice (Section 4).

This chapter presents a discussion of the three issues with respect to current design research practice. As such, the three main sections reflect on each of the issues above with the aim of examining the following questions:

\section{Experimental effects}

- What are experimental effects in the context of experimental design research?

- What is the Hawthorne effect and how does it apply to the design research field?

- What are the main experimental effects that the design researcher needs to consider when planning a study? 


\section{The Placebo Control}

- What is the placebo control and why is it important in the context of design research?

- What is the placebo controls key characteristics and how can it be applied?

\section{Linking Laboratory and Practice}

- How is experimental study related to the wider research process?

- What are the main approaches for linking experimental study and practice?

- How can these approaches be characterised in the context of design research?

\section{Experimental Effects}

The study of designers plays a key role in design research. However, the act of studying human subjects has a range of effects on their behaviour, whether the study is observational or experimental (Kazdin, 1998). Further to this, there can be confusion when deciding which elements from other fields should be adopted when designing a study (Ball and Ormerod, 2000, Reich, 1995). In addition effects on participant behaviour due to study design are often not considered in design research. This tends to have the effect of limiting the understanding of underlying variables in complex systems (Goldschmidt and Tatsa, 2005, Cross, 2004) and may lead to the inappropriate selection of control conditions (Cash et al., 2012).

In this context, these are termed experimental effects and are a key area of study in many of the fields where human subjects are a primary source of information (Patton, 2001, Glasgow and Emmons, 2007, Winter, 2008). As such, this section undertakes a brief exploration of these experimental effects and what researchers need to know when coming across them for the first time.

Within the range of experimental effects the Hawthorne effect is one of the most commonly referenced and also one of the most difficult to deal with. This difficulty arises from the fact that the Hawthorne effect is a term that, although proven to be defunct (Taris, 2006, Adair, 1984), is extremely prevalent throughout social (Leonard and Masatu, 2006), educational (Adair et al., 1989) and clinical (Verstappen et al., 2004) research. In these contexts the meaning of the Hawthorne effect has evolved to cover a whole range of more specific experimental effects, as described below (Holden, 2001, Falk and Heckman, 2009). However, 
this subtlety can be lost in translation and, as such, it is important for design researchers to understand what the Hawthorne effect is, and what it is not, in a modern experimental context.

The original Hawthorne effect emerged from a number of studies carried out and interpreted by Mayo (1933). Mayo's analysis found that, seemingly, a subject's knowledge that they were in an experiment generated a change in behaviour irrespective of any active intervention on the part of the experimenter. This interpretation gained widespread acceptance in a number of fields and became a fundamental aspect of experimental design (Macefield, 2007, Adair, 1984). However, nearly forty years after the work of Mayo, the original findings supporting the Hawthorne effect were overturned, being reinterpreted by Parsons (1974) and others (Franke and Kaul, 1978, Holden, 2001). Despite this, the Hawthorne effect has remained a key term for two main reasons - the depth and breadth of its original adoption (with some researchers still using outdated definitions (De Amici et al., 2000)) and the acknowledgement that such effects do exist, if not in the form originally described by Mayo.

This chequered history of adoption and rebuttal has lead to the current situation within the social, psychological, educational and clinical fields where there is a widespread recognition that significant non-treatment experimental effects exist (Adair et al., 1989, Diaper, 1990, Barnes, 2010) while the specific term 'Hawthorne effect' has become increasingly ambiguous with repeated re-analysis and redefinition (Taris, 2006, Chiesa and Hobbs, 2008). Thus, although the term is common, it is typically used to describe the more general effect of an experiment on the behaviour of the participant without referring to any specific effect type. In this context the design researcher can consider the Hawthorne effect as a 'catchall' type term referring to the multiple interlinked experimental effects which, depending on the study, have varying degrees of impact (Cook, 1967, Diaper, 1990) (although some degree of caution should be exercised as the term is still sometimes erroneously used in its original definition). In this general sense Adair gives a good working definition that can be used by design researchers:

Adair states that the Hawthorne effect can be generally defined as "... the problem in field experiments that, subjects' knowledge that they are in an experiment, modifies their 
behaviour from what it would have been without the knowledge [of being in an experiment]." (Adair, 1984) (p. 334)

Although the term is heavily used in other fields it is not yet embedded in the design research literature. Further, even in these fields it is accepted that due to the ambiguity of meaning and imprecise definition of the Hawthorne effect it can no-longer be accepted as a definitive description of an experimental effect and should not be reported as such (Barnes, 2010).

Therefore, the authors strongly urge design researchers to make an informed judgement of the term "Hawthorne effect" given its historical significance and role in other fields but to avoid its use in the context of modern design research experiments. Instead there are a number of more specific terms that have risen up to replace the Hawthorne effect in describing specific experimental effects. These various effects are listed and described in Table 1, which brings together reviews from several fields as well as identifying other commonly used terms. Examples of the effects described here can be found in texts, such as, Rosenthal (1976), Cook et al. (1979), Leonard and Masatu (2006) and others (McCarney et al., 2007, Chiesa and Hobbs, 2008). The placebo effect is included in this table as although it is distinct from experimental effects (being a deliberate effect used for control) it is still sometimes reported or interpreted as a Hawthorne type effect.

\begin{tabular}{|l|l|}
\hline Specific effect name & Description of effect \\
\hline $\begin{array}{l}\text { Experimenter bias } \\
\text { effect or Pygmalion } \\
\text { effect }\end{array}$ & $\begin{array}{l}\text { Researchers expect certain participants to improve and reinforce these } \\
\text { expectations (Gephart and Antonoplos, 1969, Barnes, 2010) }\end{array}$ \\
\hline Novelty & $\begin{array}{l}\text { Participants are affected by the novelty of research procedures and modify } \\
\text { their behaviour (Gephart and Antonoplos, 1969) }\end{array}$ \\
\hline $\begin{array}{l}\text { Awareness of } \\
\text { participation }\end{array}$ & $\begin{array}{l}\text { Participants are affected by awareness of the research process and modify } \\
\text { their behaviour (Gephart and Antonoplos, 1969) }\end{array}$ \\
\hline $\begin{array}{l}\text { Altered social } \\
\text { structure }\end{array}$ & $\begin{array}{l}\text { Participants interact amongst themselves and the researcher and modify } \\
\text { their behaviour (Gephart and Antonoplos, 1969) }\end{array}$ \\
\hline Hypothesis awareness & $\begin{array}{l}\text { Participants become aware of the hypothesis and modify their behaviour } \\
\text { (Adair, 1984) }\end{array}$ \\
\hline Knowledge of results & $\begin{array}{l}\text { Participants become aware of the reporting of their performance and } \\
\text { modify their behaviour as a result (Gephart and Antonoplos, 1969) }\end{array}$ \\
\hline $\begin{array}{l}\text { Demand } \\
\text { characteristics }\end{array}$ & $\begin{array}{l}\text { Participants perception of their role in a study attempt to modify their role } \\
\text { in the study (Gephart and Antonoplos, 1969) }\end{array}$ \\
\hline $\begin{array}{l}\text { Halo effect or social } \\
\text { desirability }\end{array}$ & $\begin{array}{l}\text { Participants feel the need to disguise negative behaviour or emphasise } \\
\text { positive behaviour (Green, 1977, Podsakoff et al., 2003) }\end{array}$ \\
\hline Learning effect & $\begin{array}{l}\text { Participants give more thought to the subject based on the research } \\
\text { questions and attempt to give 'correct' answers (Barnes, 2010) }\end{array}$ \\
\hline Contamination & Participants improve performance not only for topics under study but also \\
\hline
\end{tabular}




\begin{tabular}{|l|l|}
\hline $\begin{array}{l}\text { Message } \\
\text { contamination or } \\
\text { leaking effect }\end{array}$ & $\begin{array}{l}\text { for related ones (Verstappen et al., 2004) } \\
\text { intervention (Verstappen et al., 2004, Barnes, 2010) }\end{array}$ \\
\hline $\begin{array}{l}\text { John Henry effect or } \\
\text { compensatory rivalry }\end{array}$ & $\begin{array}{l}\text { Participants indirectly learn they are not receiving the intervention and } \\
\text { compensate for this lack by improving their behaviours (Barnes, 2010, Adair, } \\
1984)\end{array}$ \\
\hline Placebo effect & $\begin{array}{l}\text { Control participants interactions with specific procedures affects their } \\
\text { behaviour altering the performance of control subjects (Gephart and } \\
\text { Antonoplos, 1969) }\end{array}$ \\
\hline
\end{tabular}

Table 1: Experimental effects

These effects have significant impact on studies involving people and must be accounted for either in the design of the study or through use of control and normalisation (Diaper, 1990, Cook, 1962). This leads to the question - how can such a wide range of effects be controlled and taken into account? In this context one of the most effective and well proven ways to mitigate these experimental effects is the use of a placebo control condition (Kirk, 2009), which will be explored in the next section.

\section{The Placebo Control}

The use of placebo control techniques forms an integral part of many studies involving human subjects and is regarded as a methodological 'gold standard' in fields including: social, clinical and psychological research (Neuman, 1997, Kazdin, 1998, Tashakkori and Teddlie, 2008). The placebo has achieved this status by being one of the most effective means for mitigating the experimental effects, outlined in the previous section, (Kirk, 2009, Leber, 2000, Adair et al., 1990) as well as other effects such as expectancy and classical conditioning (Stewart-Williams, 2004, Kirsch, 2004, Price et al., 2008). Further, placebos can be used effectively in both large-scale studies and complex small sample size studies similar to those encountered in empirical design research (Torgerson et al., 2005, Wampold et al., 2007). A good working definition of a placebo is given below (emphasis added by the authors):

"placebo $n$. An assumedly inactive substance or dummy intervention administered to a control group to serve as a baseline for comparison of the effects of an active drug or intervention." (Colman, 2009) (p. 580)

Placebos have been present in some form in medicine since the 18th century, when the term was used to describe an ineffective intervention (Oxford, 2010). However, by the late 
1950 's this had evolved into the placebo concept used today in clinical research (Wampold et al., 2007, Stewart-Williams, 2004). Other fields, such as, psychology and education rapidly adopted and adapted the placebo control, leading to its use as a powerful control method since the 1950's (Leber, 2000, Adair et al., 1990).

Two key concepts underpin the placebo control: the inert intervention itself (the placebo) and the subsequent effect on the participants (the placebo effect). In this context inert means an intervention that has no active element - as defined by the study hypothesis - but is otherwise identical to the actual treatment intervention. This simulation of the treatment intervention whilst removing the active element allows for the isolation of the effect of the active element from any other experimental effects - see the example below.

\section{Placebo Example}

The recent work of Cash et al. (2012) aimed to test the impact of giving information on the energy consumption habits of users to designers. This was communicated to the participating designers via an ethnographic video administered by the researcher. As such, the treatment intervention was the ethnographic video while the active element was the specific information on energy consumption habits. In this case the placebo condition could be characterised as an edited version of the video with the specific energy consumption information removed and all other variables (e.g. length and tone) kept the same.

The second fundamental concept is that of the placebo effect, describing the change in behaviour displayed by recipients of the placebo intervention. These effects can range from specific physical reactions (Ross and Olson, 1981) to improved classroom behaviour (Eastman and Rasbury, 1981) and are considered to derive from incidental factors associated with the intervention (Ernst and Resch, 1995). These can be characterised as the combined result of the experimental effects described in Section 2 and the incidental effects of the experimental procedure itself e.g. the disruption of watching the video in the example above, or simply the additional interaction with the researchers (Paterson and Dieppe, 2005, Geers et al., 2005). Thus despite being described as inert the placebo has a clear and demonstrable effect on participants. As such, a placebo can only be considered to be inert with respect to the active element, with the remaining effects of its implementation making up the placebo effect (Moerman and Jonas, 2002, Miller and Kaptchuk, 2008). This isolation of experimental variables is illustrated in Figure 1, where a normal no-treatment control, a 
placebo control and an active treatment are compared. Here contextual variables refer to the overall processes of the study e.g. setup and general procedure. As shown in the figure, typical no-treatment controls only cover the incidental contextual variables while the placebo control covers all of the incidental variables, both contextual and related to the intervention. Thus the active variables can only be fully isolated by subtracting the placebo from the treatment condition.

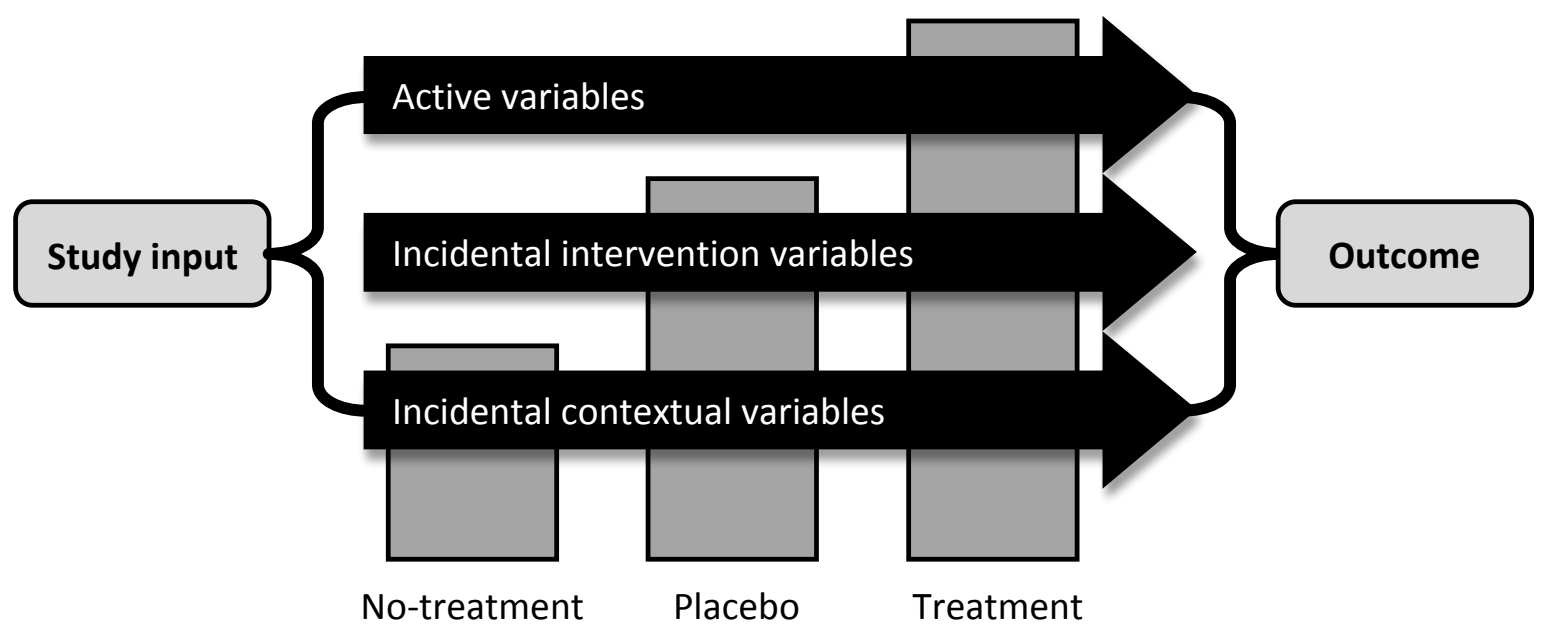

Figure 1: A breakdown of the variables assessed by each experimental condition

In terms of implementing a placebo control in the context of design research there are several key points to be considered when designing an inert (with respect to the study hypothesis) intervention. Some more examples are given below to illustrate some of the points in actual studies.

1. Establishing what is being tested and therefore defining the active element in the experiment. This is highly dependent on a clear and well-defined hypothesis.

\section{Active Element Example}

Two studies, sharing similar characteristics, each used a short film to give information to study participants as their treatment intervention. However, despite this similarity the active element can be significantly different. The active element in study one was the information content of the video (Douglas et al., 1999). Here, an analogues example in design could be the affect different types inspiration cards (biological, technical, random etc.) have on a designer's creativity. In study two the active element was the format of the information video, paper etc. (Fichten and Wright, 1983). A design example in this case might be the influence the format of a boundary object has on its role in facilitating the communication of 
engineering knowledge (Carlile, 2002). Thus, despite the similarities between the studies a placebo for study one would be significantly different from a placebo for study two.

2. Establish the context of this active element with respect to the overall experimental setup and the treatment intervention. Identify what the placebo will simulate by describing the treatment intervention in detail and isolating the active elements where possible.

3. Define the inert placebo intervention by mimicking the treatment intervention whilst eliminating the active elements that are under investigation. This can be achieved by replacing the active elements with ones of a similar theme and type (Schinke and Gilchrist, 1985, Fulda et al., 2007, Eastman and Rasbury, 1981).

\section{Inert Example}

Douglas et al. (1999) identify specific mental health information as their active element, for their inert intervention they use general health information delivered in the same format and with the same level of researcher contact. A similar example in the design domain might be the substitution of specific user needs information with generic information about the target population during a design exercise (Cash et al., 2012). Further, Smith et al. (2006) identify their active element as specific learning exercises delivered during health visits by nurses. In this case the inert intervention was the introduction of generic healthy eating advice during the periods of the health visit previously used for the specific learning exercises. Here, an analogues example in the design domain might be the testing of a specific design method e.g. the TRIZ contradiction matrix (Altsuller et al., 1997) verses giving information detailing a generic design process e.g. the double diamond (Design-Council, 2006).

Due to the difficulty in defining and effectively replacing active elements in the complex situations referred to above, it is important to develop the placebo control through iterative testing. A common issue encountered at this stage is that although the inert intervention successfully mimics the treatment intervention in terms of style it does not mimic it in terms of participant attention. This can happen when the participants identify the placebo as not relevant and dismiss it. As such, prototype studies and other elements of good experimental design - particularly double blind design - are essential to the effective refinement and implementation of placebo controls. Building on this point it is important to note that no 
single technique is capable of mitigating all the challenges associated with complex humanfocused design research studies and thus the placebo must be considered in conjunction with overall experimental good practice (Erceg-Hurn and Mirosevich, 2008, Song et al., 2009, Mattocks and Horwitz, 2000). Further, there are several factors that must be considered when implementing a placebo as discussed at length by Hrobjartsson (2002). Key points with respect to design research can be synthesised from the literature and are highlighted below:

1. Ethical issues: In particular the administration of inert treatments when working treatments exist can be problematic in certain contexts (Puzynski, 2004).

2. Specificity: Placebo conditions must be developed for each study and hypothesis under test (Ernst and Resch, 1995, Louhiala and Puustinen, 2008) limiting the scope of a placebo's applicability (Bracey, 2004, Torgerson and Torgerson, 2003).

3. Complexity: It can be difficult to isolate the active elements if suitable theory (or explanatory framework) is not available or the hypothesis is not clearly defined (Moerman and Jonas, 2002, Miller and Kaptchuk, 2008).

Despite these issues the randomised, placebo controlled trial has become a critical tool for establishing effective experimental control and fundamentally necessary for making causal claims when human subjects are involved (Price et al., 2008, Quitkin, 1999, Riehl, 2006, Adair et al., 1990) - even in extremely complex situations such as those encountered by design researchers (Kazdin, 1998, Cash et al., 2012). However, even where the placebo is effectively deployed there can still be a significant gap between results generated in a laboratory and the ultimate impact in practice. As such, the final area discussed in this chapter will examine how these two disparate contexts - experimental study and practice can be linked and examined cohesively.

\section{$4 \quad$ Linking Laboratory and Practice}

The link between laboratory study and actual practice is often complex and multi-faceted, leading to difficulty in assessing external validity and applying findings (Eifert et al., 1999, Friedman, 2000). However, this does not diminish the importance of high quality experimentation in the wider research context, as emphasised by Brown (1992). As such, this section will explore the context of the experimental study, with respect to the research process, discuss how external validity can be developed and present a number of 
approaches for integrating experimental work into a more cohesive understanding of practice.

In terms of the process of developing understanding there are two main elements that can be described: theory building and theory testing (Eisenhardt, 1989). Eisenhardt has developed this work to describe it as a cyclical research process based on replication: data allows inductive theory building, this is then examined by deductive theory testing, resulting in new data and so on (Eisenhardt and Graebner, 2007). Figure 2 depicts this process with theory being continually derived, tested and then modified or replaced.

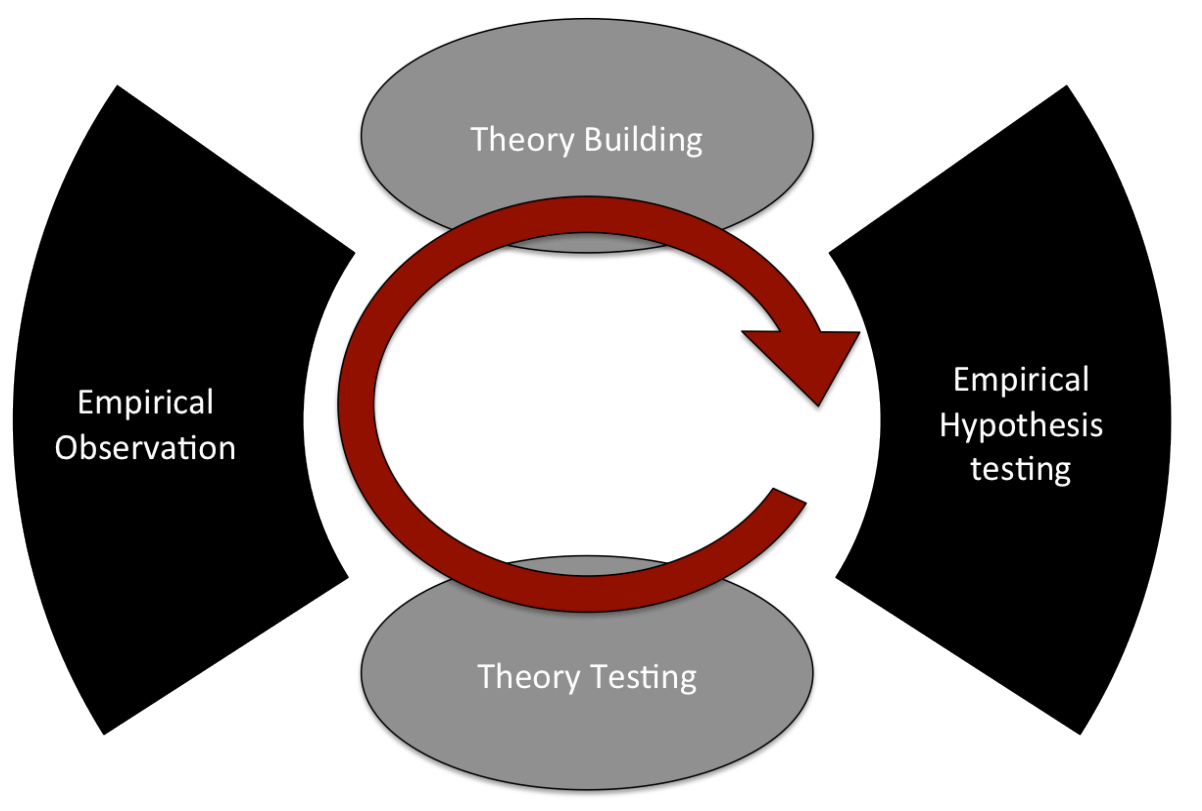

Figure 2: The cyclical theory building process

This dynamic process of theory building/testing supported by empirical study is critical to generating meaningful understanding (Carroll and Swatman, 2000) but also in defining and deploying appropriate research methods (Flynn et al., 1990). A clue as to how experimentation fits into this cycle is offered by Snow and Thomas (2007) who distil the process into three key steps for theory building/testing: description, explanation and prediction. These three steps give a process of describing variables/metrics, developing relationships/testing subsequent hypotheses and predicting future events/testing competing theories as discussed in detail by Wacker (1998).

In this context experimentation plays a fundamental role in theory testing - particularly in the testing of specific hypotheses related to theoretically identified variables. Similarly, descriptive or grounded studies (Simon et al., 1995) play an important role in theory 
building. However, it quickly becomes apparent that isolated experimental/observational studies alone, are not sufficient when considering complex multi-variable systems, such as those encountered in design research. This is particularly important where individual variables cannot be isolated or tested effectively.

In this sense there is need for a final bridge between experimental testing of individual variables and application in the multi-variable context of practice (Flynn et al., 1990, Levin and O'Donnell, 1999, Cash, 2012). This is exceptionally relevant in applied research areas, such as design research, where findings must be applicable in real situations where the starting conditions and wider context are often poorly understood and difficult to meaningfully qualify, if at all.

Based on these considerations it quickly becomes apparent that a key driver for research in the applied sciences is building on and integrating fundamental experimentation and the reality of practice (Messick, 1994, Levin and O'Donnell, 1999, Sandoval and Bell, 2004). Both Messick (1994) and Levin and O'Donnell (1999) highlight the importance of extending experimental study into integrated studies in order to fulfil the need for rich, cohesive evidence and to close the loop with practice. This leads to three main requirements when aiming to bridge laboratory and practice:

- Understanding and mitigating subjectivity. In particular Levin O'Donnell (1999) highlight the problem of research becoming: 'examine, select, prescribe' based on researcher bias rather than evidence.

- Integrating context into the research process. This is critical for developing generalisability and allowing for re-examination (Jonas, 2006).

- The need to underpin practical impact with fundamental understanding through rich multifaceted study (Eisenhardt, 1989, Eisenhardt and Graebner, 2007) and explanatory models or frameworks (Dorst, 2008).

In order to fulfil these requirements there are a number of approaches for combining and extending experimental studies. Most significant and well-established of these is the randomised, controlled trial, referred to as the 'gold standard' and considered the strongest form of evidence (Grimes and Schulz, 2002) in clinical research (Kazdin, 1998, Hulley et al., 2007). This type of study builds on a proposed explanatory model to take a representative 
population and randomly assigns participants to either a treatment or a placebo control. These conditions are then administered using a double blind design with results being recorded over significant periods of time - sometimes over decades. It is important to note that these trials do not occur in a vacuum, building on significant laboratory testing of individual elements before being considered ready for trial. This integrated approach has evolved from a research philosophy, which emphasises the link between research and reality (Hulley et al., 2007). Further, experimental effects are important and well acknowledged in clinical research and have played a key role in shaping methods, such as the placebo control discussed in Section 3 (McCarney et al., 2007, Taris, 2006).

Taking a lead from this well established approach in clinical research Levin and O'Donnell (1999) propose randomised trials for education research. In their proposed approach Levin and O'Donnell attempt to synthesise the best qualities of both applied and fundamental techniques by building on extensive descriptive studies of practice and experimental studies of specific variables in the laboratory. They then use these to define cohesive longitudinal trials, which can be effectively deployed in practice. Levin and O'Donnell (1999) developed this into 'CAREful': evidence is based on appropriate Comparison, outcomes can be produced Again and again, direct Relationships can be established between intervention and outcome, and all other competing explanations can be Eliminated.

Alternatively an approach can be generated that aims to explicitly characterise the differences between behaviour in the laboratory and practice in order to directly apply laboratory results. This has been attempted in a number of fields with varying degrees of success. For example, Nordgren and Morris-McDonnell (2010) examine how people judge the severity of others' crimes, Bolton and Ockenfels (2008) look at trading behaviour in online auctions, and Levitt and List (2007) measure social preferences in the laboratory compared to the real world. Most recently in the design research context Cash et al. (2013) undertook a similar approach when assessing designer activity in a range of commonly studied design situations, including, information seeking, ideation and design review. In this study Cash et al. also used an intermediary study between practice and laboratory in order to further link the two contexts.

The use of intermediary studies has been highlighted by a number of authors as a key means of investigating complex situations. Both Bonetti et al. (2010) in behavioural research and 
Marsden (2007) in education research have adopted the approach of developing intermediary studies - taking an experimental approach into a practice context, while Bolton and Ockenfels (2008) describe this as losing control in a controlled way. Although this approach can be important it is most effective when based on substantive theory, and rigorous explanative models (Dorst, 2008), allowing key factors to be controlled as well as offering predictions to be examined (Levitt and List, 2007), and also used in combination with the other main approaches.

In summary the two main means for bridging the gap between laboratory and practice can be characterised as:

- Extensive longitudinal, randomised, controlled trials deployed in the context of practice.

- Direct comparison of specific events, situations or behaviours in the context of laboratory and practice. These are often underpinned by the use of intermediary studies or combined with the longitudinal trials outlined above.

Although the examples presented are significantly different in their approach they are by no means mutually exclusive. For example, it has been argued that strong evidence can be generated by running a longitudinal trial with a shallow level of data capture which is supplemented by in depth experimental studies of specific events or variables (Bolton and Ockenfels, 2008). As such, this would constitute some combination of the two approaches described above, being both longitudinal and directly comparative. Further, as the work of Cash (2012) highlights, there are significant gains to be made in the application of experimental work by integrating multiple methods of study and streams of evidence (building on the ideal of triangulation as described by Denzin and Lincoln (1994)) in order to give a richer understanding of a phenomena in practice without losing the deeper insight available through the study of specific variables in the laboratory.

\section{Conclusions}

As highlighted in the introduction to this chapter experimental studies play a key role in design research, however, there is a critical lack of field specific discussion of experimental methods and methodology. This "field specific" research issue has been decomposed into three main areas - experimental effects, the placebo control and linking laboratory and practice. In each area, key points have been distilled in order to set the stage for further discussion and development by the design researcher. However, it is important to note that 
each subject discussed here is deserving of a specific chapter or even a dedicated book. As has been highlighted in this paper there are many weighty and significant works (noted again here for clarity) on these topics in fields such as psychology (Kirk, 2009, Tashakkori and Teddlie, 2008), social science (Robson, 2002, Neuman, 1997) and clinical research (Kazdin, 1998, Denzin and Lincoln, 1994). However, this is beyond the scope of the discussion developed in this chapter. It is simply worth noting that any design researcher aspiring to take their experimental methods to the next level of rigour can no longer afford to ignore the significant work in other fields.

In this context the authors suggest some summary answers to the questions posed in the introduction:

\section{Experimental Effects}

- The importance and extent of experimental effects in design research experimentation cannot be over stated as they affect every aspect of studying human participants.

- The importance of the Hawthorne effect as a general descriptor for experimental effects must be acknowledged when reviewing other fields but it is important to realise the term is effectively defunct and should not be used when describing specific effects in the context of design research.

- There are a large number of important effects that need to be considered when designing a study. These have been distilled and are summarised in Table 1. This can be used as a useful checklist.

\section{The Placebo Control}

- The placebo is fundamentally underpinned by the idea of an inert intervention, which is based on the active elements defined in a study's hypothesis.

- The placebo control is key to mitigating the experimental effects described in Section 2 and forms a fundamental technique in many fields and in particular in many of the fields closely related to design research.

\section{Linking Laboratory and Practice}

- The role of experimentation serves to support both theory building and theory testing both of which must be considered in order to develop meaningful understanding. 
- There seem to be two key approaches for linking experimental study to practice: Extensive, longitudinal trials drawing on and integrating elements from both experimental and observational methods, and Direct comparison of specific situations or variables. Further, these approaches can be combined cohesively to give significant insight into practice without sacrificing the detailed examination possible through laboratory study.

The purpose of this chapter has been to bring inputs from other disciplines into the design research community to help in the development of greater scientific rigour and the improvement of experimental methods and methodology. In particular, this supports the cyclical theory building process (Figure 2), which is the critical outcome of individuals and teams' research.

\section{References}

ADAIR, J. G. (1984) The Hawthorne effect: A reconsideration of the methodological artifact. Journal of Applied Psychology, 69, 334-345.

ADAIR, J. G., SHARPE, D. \& HUYNH, C. L. (1989) Hawthorne control procedures in educational experiments: A reconsideration of their use and effectiveness. Review of Educational Research, 59, 215-228.

ADAIR, J. G., SHARPE, D. \& HUYNH, C. L. (1990) The placebo control group: An analysis of its effectiveness in educational research. The Journal of Experimental Education, 59, 6786.

ALTSULLER, G. S., SHULYAK, L., RODMAN, S. \& FEDOSEEV, U. (1997) 40 principles: TRIZ keys to technical innovation, Worcester, MA, Technical Innovation Center, Inc.

ANTONSSON, E. K. (1987) Development and testing of hypotheses in engineering design research. Journal of Mechanisms, Transmissions, and Automation in Design, 109, 153-154.

BALL, L. J. \& ORMEROD, T. C. (2000) Applying ethnography in the analysis and support of expertise in engineering design. Design Studies, 21, 403-421.

BAR-ELI, S. (2013) Sketching profiles: Awareness to individual differences in sketching as a means of enhancing design solution development. Design Studies, 34, 472-493.

BARNES, B. R. (2010) The Hawthorne effect in community trials in developing countries. International Journal of Social Research Methodology, 13, 357-370.

BLESSING, L. T. M. \& CHAKRABARTI, A. (2009) DRM, a Design Research Methodology, New York, Springer.

BOLTON, G. E. \& OCKENFELS, A. (2008) Does laboratory trading mirror behaviour in real world markets?: Fair bargaining and competitive bidding on EBay, CESifo.

BONETTI, D., JOHNSTON, M., CLARKSON, J. E., GRIMSHAW, J., PITTS, N. B., ECCLES, M., STEEN, N., THOMAS, R., MACLENNAN, G. \& GLIDEWELL, L. (2010) Research article applying psychological theories to evidence-based clinical practice: Identifying factors predictive of placing preventive fissure sealants. Behaviour, 16, 18-23.

BRACEY, G. W. (2004) The trouble with research, part 2. Phi Delta Kappan, 85, 635-636. 
BROWN, A. L. (1992) Design experiments: Theoretical and methodological challenges in creating complex interventions in classroom settings. The Journal of the Learning Sciences, 2, 141-178.

CAI, H., DO, E. Y. L. \& ZIMRING, C. M. (2010) Extended linkography and distance graph in design evaluation: an empirical study of the dual effects of inspiration sources in creative design. Design Studies, 31, 146-168.

CARLILE, P. R. (2002) A pragmatic view of knowledge and boundaries: Boundary objects in new product development. Organization Science, 13, 442-455.

CARROLL, J. M. \& SWATMAN, P. A. (2000) Structured-case: A methodological framework for building theory in information systems research. European journal of information systems, 9, 235-242.

CASH, P., ELIAS, E. W. A., DEKONINCK, E. \& CULLEY, S. J. (2012) Methodological insights from a rigorous small scale design experiment. Design Studies, 33, 208-235.

CASH, P., HICKS, B. J. \& CULLEY, S. (2013) A comparison of designer activity using core design situations in the laboratory and practice. Design Studies, 34, 575-611.

CASH, P. J. (2012) Characterising the relationship between practice and laboratory-based studies of designers for critical design situations. PhD Doctoral Thesis, Dept. of Mechanical Engineering. Bath, University of Bath.

CHIESA, M. \& HOBBS, S. (2008) Making sense of social research: How useful is the Hawthorne Effect? European Journal of Social Psychology, 38, 67-74.

COLMAN, A. M. (2009) Oxford dictionary of psychology. New York: Oxford University.

COOK, D. L. (1962) The Hawthorne effect in educational research. The Phi Delta Kappan, 44, 116-122.

COOK, D. L. (1967) The impact of the Hawthorne effect in experimental designs in education research - Final report. IN U.S. DEPARTEMENT OF HEALTH, E. A. W. (Ed.). Ohio State University, Columbus.

COOK, T. D., CAMPBELL, D. T. \& DAY, A. (1979) Quasi-experimentation: Design \& analysis issues for field settings, Boston, USA, Houghton Mifflin.

CORREMANS, J. A. M. (2009) Measuring the effectiveness of a design method to generate form alternatives: an experiment performed with freshmen students product development. Journal of Engineering Design, 22, 259-274.

CROSS, N. (2004) Expertise in design: An overview. Design Studies, 25, 427.

CROSS, N. (2007) Forty years of design research. Design Studies, 28, 1-4.

DE AMICI, D., KLERSY, C., RAMAJOLI, F., BRUSTIA, L. \& POLITI, P. (2000) Impact of the Hawthorne Effect in a longitudinal clinical study: The case of anaesthesia. Controlled Clinical Trials, 21, 103-114.

DENZIN, N. K. \& LINCOLN, Y. S. (1994) Handbook of qualitative research, Thousand Oaks, CA, USA, Sage.

DESIGN-COUNCIL (2006) Double diamond design process model [Online]. http://www.designcouncil.org.uk/designprocess.

DIAPER, G. (1990) The Hawthorne effect: A fresh examination. Educational Studies; Dorchester-on-Thames, 16, 261-267.

DIXON, J. R. (1987) On research methodology towards a scientific theory of engineering design. Artificial Intelligence for Engineering Design, Analysis and Manufacturing, 1, 145-157.

DORST, K. (2008) Design research: a revolution-waiting-to-happen. Design Studies, 29, 4-11.

DOUGLAS, B. C., NOBLE, L. M. \& NEWMAN, P. S. (1999) Improving the accuracy of patients' expectations of the psychiatric out-patient consultation. Psychiatric Bulletin, 23, 425-427. 
EASTMAN, B. G. \& RASBURY, W. C. (1981) Cognitive self-instruction for the control of impulsive classroom behaviour: Ensuring the treatment package. Journal of Abnormal Child Psychology, 9, 381-387.

EIFERT, G. H., FORSYTH, J. P., ZVOLENSKY, M. J. \& LEJUEZ, C. W. (1999) Moving from the laboratory to the real world and back again: Increasing the relevance of laboratory examinations of anxiety sensitivity. Behavior Therapy, 30, 273-283.

EISENHARDT, K. M. (1989) Building theories from case study research. Academy of Management Review, 14, 532-550.

EISENHARDT, K. M. \& GRAEBNER, M. E. (2007) Theory building from cases: Opportunities and challenges. Academy of Management Journal, 50, 25-32.

ERCEG-HURN, D. M. \& MIROSEVICH, V. M. (2008) Modern robust statistical methods: An easy way to maximise the accuracy and power of your research. American Psychologist, 63, 591-601.

ERNST, E. \& RESCH, K. L. (1995) Concept of true and perceived placebo effects. BMJ British Medical Journal, 311, 551-553.

FALK, A. \& HECKMAN, J. (2009) Lab experiments are a major source of knowledge in the social sciences. Science, 326, 535-538.

FICHTEN, C. S. \& WRIGHT, J. (1983) Problem-solving skills in happy and distressed couples: Effects of videotape and verbal feedback. Journal of Clinical Psychology, 39, 340-352.

FINGER, S. \& DIXON, J. R. (1989a) A review of research in mechanical engineering design. Part I: Descriptive, prescriptive, and computer-based models of design processes. Research in Engineering Design, 1, 51-67.

FINGER, S. \& DIXON, J. R. (1989b) A review of research in mechanical engineering design. Part II: Representations, analysis, and design for the life cycle. Research in Engineering Design, 1, 121-137.

FLYNN, B. B., SAKAKIBARA, S., SCHROEDER, R. G., BATES, K. A. \& FLYNN, E. J. (1990) Empirical research methods in operations management. Journal of Operations Management, 9, 250-284.

FRANKE, R. H. \& KAUL, J. D. (1978) The Hawthorne experiments: First statistical interpretation. American Sociological Review, 43, 623-643.

FRIEDMAN, K. (2000) Creating design knowledge: From research into practice. IDATER 2000 Conference. Loughborough, UK, Loughborough University.

FULDA, K. G., SLICHO, T. \& STOLL, S. T. (2007) Patient expectations for placebo treatments commonly used in osteopathic manipulative treatment (OMT) clinical trials: A pilot study. Osteopathic Medicine and Primary Care, 1, 3-10.

GEERS, A. L., HELFER, S. G., KOSBAB, K., WEILAND, P. E. \& LANDRY, S. J. (2005) Reconsidering the role of personality in placebo effects: Dispositional optimism, situational expectations, and the placebo response. Journal of Psychosomatic Research, 58, 121-127.

GEPHART, W. J. \& ANTONOPLOS, D. P. (1969) The effects of expectancy and other researchbiasing factors. The Phi Delta Kappan, 50, 579-583.

GLASGOW, R. E. \& EMMONS, K. M. (2007) How can we increase translation of research into practice? Types of evidence needed. Annual Review of Public Health, 28, 413-433.

GOLDSCHMIDT, G. \& TATSA, D. (2005) How good are good ideas? Correlates of design creativity. Design Studies, 26, 593-611.

GREEN, L. W. (1977) Evaluation and measurement: Some dilemmas for health education. American Journal of Public Health, 67, 155-161.

GRIMES, D. A. \& SCHULZ, K. F. (2002) An overview of clinical research: The lay of the land. The Lancet, 359, 57-61.

HOLDEN, J. D. (2001) Hawthorne effects and research into professional practice. Journal of Evaluation in Clinical Practice, 7, 65-70. 
HROBJARTSSON, A. (2002) What are the main methodological problems in the estimation of placebo effects? Journal of Clinical Epidemiology, 55, 430-435.

HULLEY, S. B., CUMMINGS, S. R., BROWNER, W. S., GRADY, D., HEARST, N. \& NEWMAN, T. D. (2007) Designing clinical research, Philadelphia, Pennsylvania, U.S., Lippincott Williams \& Wilkins.

JONAS, W. (2006) Research through DESIGN through research: A problem statement and a conceptual sketch. Design Research Society International Conference. Lisbon, Portugal.

KAZDIN, A. E. (1998) Research design in clinical psychology, Needham Heights, MA, USA, Allyn \& Bacon.

KIRK, R. E. (2009) Experimental design, London, UK, Sage Publications.

$\mathrm{KIRSCH}$, I. (2004) Conditioning, expectancy, and the placebo effect: comment on StewartWilliams and Podd (2004). Psychological Bulletin, 130, 341-343.

LEBER, P. (2000) The use of placebo control groups in the assessment of psychiatric drugs: an historical context. Biological Psychiatry, 47, 699-706.

LEONARD, K. \& MASATU, M. C. (2006) Outpatient process quality evaluation and the Hawthorne Effect. Social Science \& Medicine, 63, 2330-2340.

LEVIN, J. R. \& O'DONNELL, A. M. (1999) What to do about educational research's credibility gaps? Issues in education, 5, 177-229.

LEVITT, S. D. \& LIST, J. A. (2007) What do laboratory experiments measuring social preferences reveal about the real world? The Journal of Economic Perspectives, 21, 153-174.

LOUHIALA, P. \& PUUSTINEN, R. (2008) Rethinking the placebo effect. Medical humanities, 34, 107-109.

MACEFIELD, R. (2007) Usability studies and the Hawthorne effect. Journal of Usability Studies, 2, 145-154.

MARSDEN, E. (2007) Can educational experiments both test a theory and inform practice? British Educational Research Journal, 33, 565-588.

MATTOCKS, K. M. \& HORWITZ, R. I. (2000) Placebos, active control groups, and the unpredictability paradox. Biological Psychiatry, 47, 693-698.

MAYO, E. (1933) The human problems of an industrial civilisation, London, Routledge.

MCCARNEY, R., WARNER, J., ILIFFE, S., VAN HASELEN, R., GRIFFIN, M. \& FISHER, P. (2007) The Hawthorne effect: a randomised, controlled trial. BMC Medical Research Methodology, 7, 30-37.

MESSICK, S. (1994) The interplay of evidence and consequences in the validation of performance assessments. Educational Researcher, 23, 13-23.

MILLER, F. G. \& KAPTCHUK, T. J. (2008) The power of context: Reconceptualizing the placebo effect. Royal Society of Medicine (Great Britain). Journal of the Royal Society of Medicine, 101, 222-225.

MOERMAN, D. E. \& JONAS, W. B. (2002) Deconstructing the placebo effect and finding the meaning response. Annals of Internal Medicine, 136, 471-476.

NEUMAN, L. (1997) Social research methods: Qualitative and quantitative approaches, Boston, USA, Allyn and Bacon.

NORDGREN, L. F. \& MORRIS MCDONNELL, M. H. (2010) The Scope-Severity paradox: Why doing more harm Is judged to be less harmful. Social Psychological and Personality Science.

OXFORD (2010) Oxford English Dictionary [Online]. Online. DRAFT REVISION June 2010 ed. Oxford, Oxford University Press.

PARSONS, H. M. (1974) What happened at Hawthorne? Science, 183, 922-932. 
PATERSON, C. \& DIEPPE, P. (2005) Characteristic and incidental (placebo) effects in complex interventions such as acupuncture. BMJ British Medical Journal (Clinical research ed.), 330, 1202-1205.

PATTON, M. Q. (2001) Qualitative research \& evaluation methods, Thousand Oaks, CA, Sage.

PODSAKOFF, P. M., MACKENZIE, S. B., LEE, J.-Y. \& PODSAKOFF, N. P. (2003) Common method biases in behavioural research: A critical review of the literature and recommended remedies. Journal of Applied Psychology, 88, 879-903.

PRICE, D. D., FINNISS, D. G. \& BENEDETTI, F. (2008) A comprehensive review of the placebo effect: recent advances and current thought. Annual Review of Psychology, 59, 565590.

PUZYNSKI, S. (2004) Placebo in the investigation of psychotropic drugs, especially antidepressants. Science and Engineering Ethics, 10, 135-142.

QUITKIN, F. M. (1999) Placebos, drug effects, and study design: A clinician's guide. The American Journal of Psychiatry, 156, 829-836.

REICH, Y. (1994) Annotated bibliography on research methodologies. Al EDAM (Artificial Intelligence for Engineering Design, Analysis and Manufacturing), 8, 355-366.

REICH, Y. (1995) The study of design research methodology. Transactions-American Society of Mechanical Engineers Journal of Mechanical Design, 117, 211-214.

RIEHL, C. (2006) Feeling better: A comparison of medical research and education research. Educational Researcher, 35, 24-29.

ROBSON, C. (2002) Real world research, Chichester, Wiley.

ROSENTHAL, R. (1976) Experimenter effects in behavioural research, Chichester, John Wiley \& Sons Inc.

ROSS, M. \& OLSON, J. M. (1981) An expectancy-attribution model of the effects of placebos. Psychological Review, 88, 408-437.

SANDOVAL, W. A. \& BELL, P. (2004) Design-based research methods for studying learning in context: Introduction. Educational Psychologist, 39, 199-201.

SCHINKE, S. P. \& GILCHRIST, L. D. (1985) Preventing substance abuse with children and adolescents. Journal of Consulting and Clinical Psychology, 53, 596-602.

SIMON, A., SOHAL, A. \& BROWN, A. (1995) Generative and case study research in quality management. The International Journal of Quality \& Reliability Management, 13, 3242.

SMITH, C. E., DAUZ, E. R., CLEMENTS, F., PUNO, F. N., COOK, D., DOOLITTLE, G. \& LEEDS, W. (2006) Telehealth services to improve nonadherence: A placebo-controlled study. Telemedicine Journal and E-health, 12, 289-296.

SNOW, C. C. \& THOMAS, J. B. (2007) Field research methods in strategic management: Contributions to theory building and testing. Journal of Management Studies, 31, 457-480.

SONG, F., LOKE, Y. K., WALSH, T., GLENNY, A.-M., EASTWOOD, A. J. \& ALTMAN, D. G. (2009) Methodological problems in the use of indirect comparisons for evaluating healthcare interventions: survey of published systematic reviews. BMJ British Medical Journal (Clinical research ed.), 338, 932-935.

STEMPFLE, J. \& BADKE-SCHAUB, P. (2002) Thinking in design teams-an analysis of team communication. Design Studies, 23, 473-496.

STEWART-WILLIAMS, S. (2004) The placebo effect: Dissolving the expectancy versus conditioning debate. Psychological Bulletin, 130, 324-340.

TARIS, T. W. (2006) Bricks without clay: On urban myths in occupational health psychology. Work and Stress, 20, 99-104.

TASHAKKORI, A. \& TEDDLIE, C. (2008) Foundations of mixed methods research: Integrating quantitative and qualitative approaches in the social and behavioral sciences, Thousand Oaks, CA, Sage. 
TORGERSON, C. J., TORGERSON, D. J., BIRKS, Y. F. \& PORTHOUSE, J. (2005) A comparison of randomised controlled trials in health and education. British Educational Research Journal, 31, 761-785.

TORGERSON, D. J. \& TORGERSON, C. J. (2003) Avoiding bias in randomised controlled trials in educational research. British Journal of Educational Studies, 51, 36-45.

VERSTAPPEN, W. H. J. M., WEIJDEN, T., RIET, G., GRIMSHAW, J., WINKENS, R. \& GROL, R. P. T. M. (2004) Block design allowed for control of the Hawthorne effect in a randomised controlled trial of test ordering. Journal of Clinical Epidemiology, 57, 1119-1123.

WACKER, J. G. (1998) A definition of theory: Research guidelines for different theorybuilding research methods in operations management. Journal of Operations Management, 16, 361-385.

WAMPOLD, B. E., IMEL, Z. E. \& MINAMI, T. (2007) The story of placebo effects in medicine: Evidence in context. Journal of Clinical Psychology, 63, 379-390.

WINTER, R. (2008) Design science research in Europe. European Journal of Information Systems, 17, 470-475. 